Theories \& Applications, the International Edition

Printed Version: (ISSN 2090-5262)

Online Version: (ISSN 2090-5270)

July 2013, Volume 3, No. 2 Pages (23 - 29)

\title{
Biological Profile as One of Selection Parameters for Speedball Female Players
}

\author{
Seham Farouk Ismail*
}

\begin{abstract}
This research aims to identify the biological characteristics of speedball of national team female players and then develop a biological profile, which may be used for

Researcher used descriptive approach with screening method as it is relevance to for research nature and fulfilling its objectives and queries.

Research society represented in speedball players registered in Egypt speedball federation who totaled to (12) female players, researcher selected ransomly from them (9) players to represent the research sample

Researcher collected data regarding: Morphological measurements (body weight, length, circumferences, depths, widths, body fat percentage, capacity, maximum oxygen uptake, Back and legs muscles strength, grip's muscles strength, maximum speed, lactic acid, vertical jump test).

Most important result was identifying biological profile fro speedball female players, most important recommendation was giving more interest to selection process for speedball due to its importance in proper direction for training process.
\end{abstract}

\section{Introduction}

$\mathrm{D}$ ue provide high levels sports in the modern era to scientific and technical development large, as well as for the effective application and given to the results of research and studies that have been for the choice of the individual appropriate for the nature and requirements of the activity Specialist practitioner. (24:12)

Indicates "Mohamed Nasr elddin (1998) that there are properties of general within individuals; there are special characteristics distinguish each individual, these differences appear in body structure; functional and psychological traits as individuals differ greatly in their mental level; they differ also in traits; some are unsociable, others are sociable, they also differ in their body measurements, some are fat, others are slim, some are sort, others are tall, theses differences in body measurements are due to different lengths of trunk, arms and legs, as well as shoulders and pelvis wide and other body's anthropometric measurements of the body (Mohamed Nasr, 1998: p15).

\footnotetext{
* Lecturer, Sports Health Sciences Department, Faculty of Physical Education, Minia University, Egypt.
}

"Saad Kamal Taha" (1996) argued that practicing any sport requires some biological characteristics that must be met in the athlete to achieve superiority There is no doubt that standards morphological considered one of the individual characteristics that are highly levels sports high, because every sporting activity requirements physical private distinguish it from other sports activities other, and reflected these requirements on qualities to be fulfilled by those who practice this activity, no doubtavailability of these morphological characteristics of practitioners can be given a greater opportunity to accommodate activity Specialist skills and arts, where it has become important to the availability of the appropriate objects as one of the fundamental pillars that must be met to get the players to athletic levels high (Saad Kamal: p 152).

The Farouk Rajab (1993) that soccer speed sport Egyptian which is a game of ball games and racket, a sport Egyptian practiced ball and racket using a simple device makes the ball spin maker circles its place installation (Pulley) at the center of a circular in space does not exceed a diameter of three meters asball proving the party nylon thread high length $1.5 \mathrm{~m}$ and the 
other end Sticky ring mounted at reel highest device the player performs four modes starting any of the situations the four Krgbth until the end of the situation all separates each mode and the last period to change the racket and the willingness to put the next time-halfminutes and this time left on all the players competing from all ages to achieve the principle of equality in (singles - doubles - quadruple individual types and mixed relay teams). (Farouk Rajab: p 24)

And indicates Abul Ela Abdel Fattah (1985) Biological factors are essential component in juniors' selection process and directing them to sports activities that suit their abilities and biological characteristics, It is basic determinants must be considered in selection process in its various stages. Many morphological traits such as height, weight and body components' proportions are genetic characteristics where genetics affect body growth and its shape formation, therefore many anthropometric measurements have particular importance in selection area because its large significance in prediction of what results can be achieved by youngsters (Abo ElEla Abdul Fatah, 1985:p 37).

Researcher noticed clear disturbance in selection process of female juniors for speedball sport, where selection process do not take into account biological characteristics, also the selection process does not rely on clear and accepted scientific basis but most of these heroes appear accidentally and by personal affairs, where the researcher also noticed severe lack in scientific selection process' application specially in taking morphological and physical measurements for female juniors.

This lack in selection process along with all achievements by speedball Champions invited researcher to try to identify biological characteristics for selecting female juniors for speedball sport, which in turn contribute in creating generations have been selected on scientific and objective basis, that is at the end upgrade sport, saving costs and access the fulfilling set objectives in he shortest and direct route.

Researcher - as far as she knows- didn't come through a study which has addressed identifying Results biological profile of speedball players, which in turn leads to put accurate criteria to select heroines and allow them to arrive to the best athletic levels.

\section{Research Objective}

This research aims to identify the biological characteristics of speedball of national team female players and then develop a biological profile, which may be used for appropriate selection of speedball female players in Egypt.

\section{Research Queries}

1. What are the morphological characteristics for Egypt's speedball national team female players

2. What are the physiological characteristics for Egypt's speedball national team female players

\section{Research Procedures}

\section{Research Methodology}

Researcher used descriptive approach with screening method as it is relevance to for research nature and fulfilling its objectives and queries.

\section{Research Society and Sample}

Research society represented in speedball players registered in Egypt speedball federation who totaled to (12) female players, researcher selected ransomly from them (9) Same basic study and (3) the same players scoping study and enrolled in the Egyptian Football speed in the period from $15 / 10 / 2011$ to $22 / 10 / 2011$.

\section{Research Tools}

1. Morphological measurements (body weight, length, circumferences, depths, widths, body fat percentage).

2. Physiological measurements (pulse rate, lungs vital capacity, maximum oxygen uptake, Back and legs muscles strength, grip's muscles strength, maximum speed, lactic acid, vertical jump test). (Mohamed Nasreddin Radwan ,1998, pp196,225)

\section{Statistical Treatments}

Average, median, skewness Coefficient, Standard deviation. 
Table (1)

Average, median, standard deviation and skewness coefficient of morphological variables under consideration in a female players' sample $(n=9)$

\begin{tabular}{|c|c|c|c|c|c|}
\hline Variables & $\begin{array}{c}\text { Measurement } \\
\text { unit }\end{array}$ & Average & Median & $\begin{array}{c}\text { Standard } \\
\text { Deviation }\end{array}$ & Skewness factor \\
\hline Shoulder length & $\mathrm{cm}$ & 18.44 & 19.00 & 1.33 & -0.66 \\
\hline Arm length & $\mathrm{cm}$ & 75.11 & 76.00 & 3.76 & -0.20 \\
\hline Legs length & $\mathrm{cm}$ & 96.67 & 98.00 & 5.41 & -0.58 \\
\hline Foot length & $\mathrm{cm}$ & 26.22 & 26.00 & 0.67 & -0.25 \\
\hline Shoulder width & $\mathrm{cm}$ & 38.67 & 38.00 & 2.12 & 0.97 \\
\hline Pelvis width & $\mathrm{cm}$ & 32.22 & 32.00 & 4.41 & 0.30 \\
\hline Wrist width & $\mathrm{cm}$ & 5.56 & 6.00 & 0.73 & -1.50 \\
\hline Chest circumference & $\mathrm{cm}$ & 82.89 & 88.00 & 15.23 & -2.35 \\
\hline $\begin{array}{c}\text { Abdominal } \\
\text { circumference }\end{array}$ & $\mathrm{cm}$ & 68.44 & 69.00 & 10.64 & -0.62 \\
\hline Thigh circumference & $\mathrm{cm}$ & 46.22 & 47.00 & 2.44 & -1.33 \\
\hline Buttocks circumference & $\mathrm{cm}$ & 94.56 & 98.00 & 11.10 & -2.28 \\
\hline Chest width & $\mathrm{cm}$ & 18.44 & 17.00 & 4.98 & 0.93 \\
\hline
\end{tabular}

Table (1) results reveal that skewness factors are free from un-normal distribution defects, as well between \pm 3 for all morphological variables as the results show the morphological under discussion, indicating that they follow the characteristics of research sample normal distribution curve, and that the sample is

Table (2)

Average, median, standard deviation and skewness coefficient of physiological variables under consideration in a female players' sample $(n=9)$

\begin{tabular}{|c|c|c|c|c|c|}
\hline Variables & Measurement Unit & Average & Median & Standar Deviation & Skewness factor \\
\hline Fat percentage & $\%$ & 0.25 & 0.25 & 0.03 & 0.51 \\
\hline Pulse rate & pulse/minute & 61.56 & 62.00 & 3.97 & -0.22 \\
\hline Vital capacity & $\mathrm{cm} 3$ & 4077.78 & 4100.00 & 130.17 & -0.35 \\
\hline Lactic rate & $\mathrm{mmol} / \mathrm{liter}$ & 3.99 & 3.90 & 0.68 & 0.31 \\
\hline Vertical jump test & $\mathrm{cm}$ & 34.33 & 35.00 & 2.78 & 0.01 \\
\hline Right Grip strength & $\mathrm{kg}$ & 37.22 & 37.00 & 4.38 & 0.86 \\
\hline Left Grip strength & $\mathrm{kg}$ & 33.44 & 30.00 & 7.30 & 0.68 \\
\hline 30 meter speed & $\mathrm{second}$ & 5.21 & 5.30 & 0.31 & 0.24 \\
\hline Back muscles strength & $\mathrm{kg}$ & 44.00 & 43.00 & 4.58 & 0.27 \\
\hline Legs muscle strength & $\mathrm{kg}$ & 83.33 & 80.00 & 12.25 & \\
\hline $\begin{array}{c}\text { Maximum oxygen } \\
\text { uptake }\end{array}$ & liter/minute & 3.99 & 3.90 & 0.15 & 0.56 \\
\hline
\end{tabular}

Table (2) results reveal that skewness factors are between \pm 3 for all physiological variables under discussion, indicating that they follow the free from un-normal distribution defects, as well normal distribution curve, and that the sample is

as the results show the physiological characteristics of research sample 
Table (3)

Biological profile of speedball female players

\begin{tabular}{|c|c|c|c|}
\hline Variables & Biological Profile & Variables & Biological Profile \\
\hline Shoulder length & 18.44 & Buttocks circumference & 94.56 \\
\hline Arm length & 75.11 & Chest width & 18.44 \\
\hline Legs length & 96.67 & Fat percentage & 0.25 \\
\hline Foot length & 26.22 & Pulse rate & 61.56 \\
\hline Shoulder width & 38.67 & Vital capacity & 4077.78 \\
\hline Pelvis width & 32.22 & Lactic rate & 3.99 \\
\hline Wrist width & 5.56 & Vertical jump test & 34.33 \\
\hline Chest circumference & 82.89 & Right Grip strength & 37.22 \\
\hline Abdominal circumference & 68.44 & Left Grip strength & 33.44 \\
\hline Thigh circumference & 46.22 & 30 meter speed & 5.21 \\
\hline Buttocks circumference & 94.56 & Back muscles strength & 44.00 \\
\hline
\end{tabular}

Table (3) and Figure (1), (2), (3) shows the biological criteria for selecting speedball female players

Figure (1)

Players age, training age and some biological variables

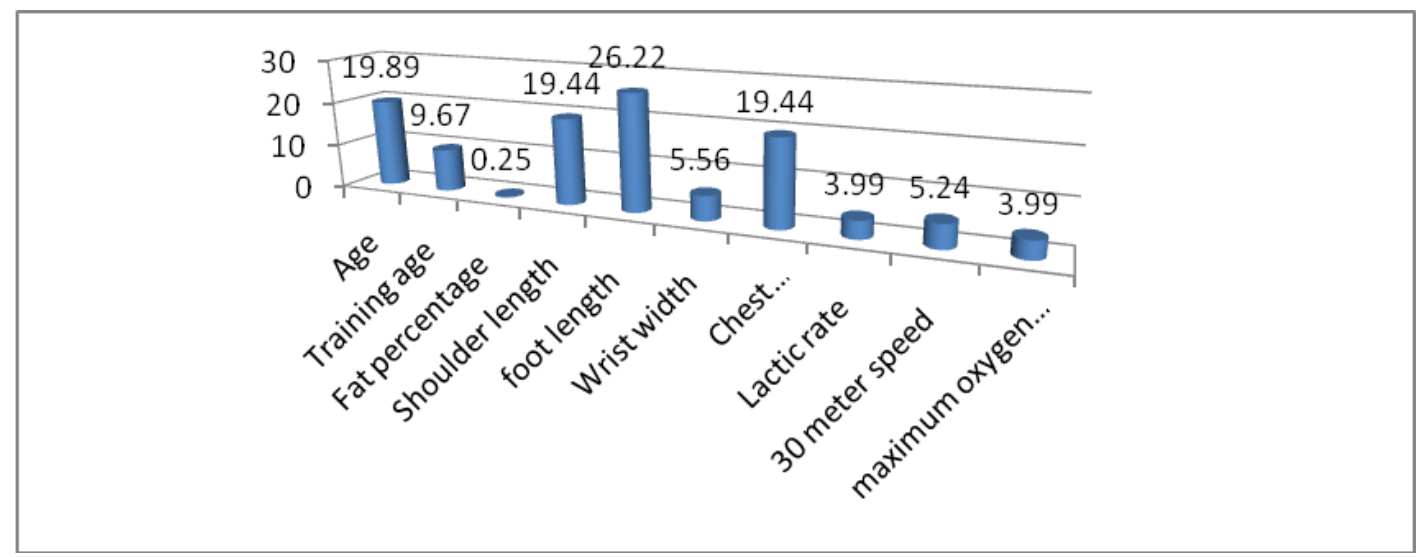

Figure (2)

Players weight and some biological variables

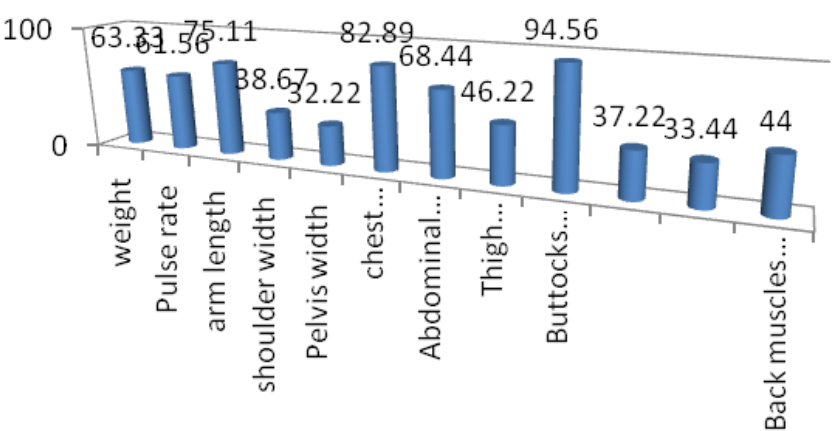


Figure (3)

Players height and some biological variables

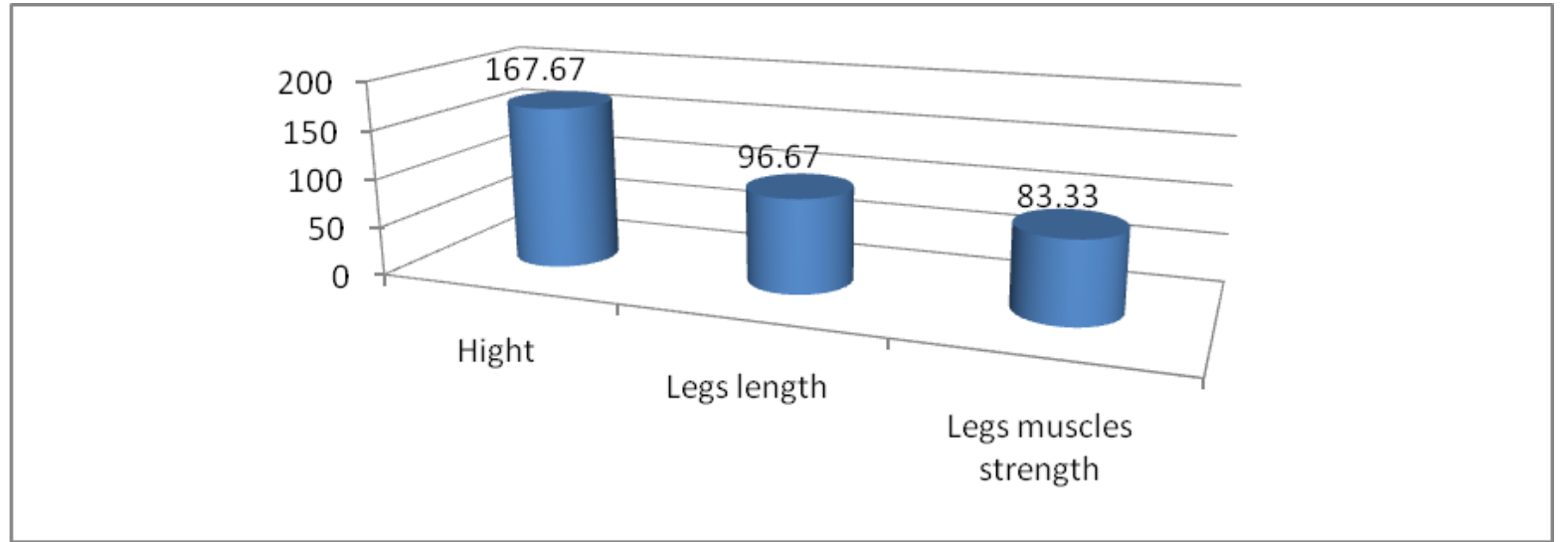

\section{Discussion}

The current research aims to identify the biological characteristics as one of selection parameters for speedball female players in Egypt, as this profile is a description of the model characteristics for high level female athletes; which an be used as a guide in selection process

Table (1) the decline of transactions sprains morphological variables under discussion between $(-3,+3)$, indicating that they are located within the curve equinoctial, as shown in the morphological characteristics of the sample under discussion (lengths - and the ocean symptoms - the proportion of fat).

Consistent results of this study with several studies such as studying Villa Helena, and Mangado Carmen (2012) (16) in that the identification of measurements physical best and physiological variables have players handball where they help to Achtyarenhen in fact play by their measurements Anthropometric to achieve the highest levels sportsand global reach.

The study findings suggest Mr. Mouawad Mr. Husseini (2001 m) ( 11 ) to put battery test "Otherubomtria, physiological, physical" for the selection of an emerging fencing, and also put equations predictive for the selection of rookies in fencing through (lengths, offers, ocean, fish skin folds)

Table (2) transactions sprains of variables physiological under confined between $(-3,+3)$, indicating that they are located within the curve equinoctial and thus sample players distributed
Aatdalia and free of defects distributions is Alaatdalah, as shown in physiological characteristics of the sample under discussion.

The results of the study" Franck leGall et, al"(2008)(4) "Gehan Yusuf Sawi" (1999) (6) to the importance of physiological measurements in the selection of junior taekwondo with Alantrbumtre measurements for players

The second objective is to use these characteristics in training process using training programs under supervision of qualified coaches; it has been possible to determine physiological and morphological characteristics levels. It is notable that morphological measurements averages are clearly in line with skill performance's nature for the study sample.

Table (3) and Figure (1), (2), (3) Criteria for selection diversity for national team players for speed and ball use in training and selection of athletes to achieve higher levels

The results of some studies suggest the importance of measurements biological and Alvesaolgah in use his Todifaa train players to reach the upper levels as a "Ashraf Nabih study" (2003) ( 2 ), "Jayasudha Katralli ‘MD , Shivaprasad S. Goudar "MD" (2012) ( 7 ) Heller-J.et, al (1998 m) (6).

Each sport activity has its own requirements, as any sport has physical, skill, tactical, and psychological requirements, good player is the one who have good integration from these requirements for access high athletic levels. Juniors has to have some parameters and characteristics. If certain parameters and characteristics are available in a junior in specific level, it may be used to predict what 
success can be achieved by this junior in certain sport activity.

Improving and developing performance level can be reached by developing physiological abilities which must be available in speedball female player ball speed by setting appropriate and scientific means and methods to develop them, this contributes to performance level development in an economical manner due to saving time and efforts .

\section{Conclusions}

1. Players' sample skewness factors for age, height, as well as anthropometric measurements were between \pm 3 which means that these variable follow normal distribution for study sample

2. Identify the biological profile of the Egyptian national team players for ball speed (the length of the trunk - total length - wrist - the body's oceans - the length of Agriculture - the proportion of fat in the body) are important in determining the selection of ball speed players.

3. Identify the physiological measurements for speed ball players are vital capacity, pulse rate, maximum oxygen uptake, lactic concentration), tests and tools for measuring body measurements are: Restameter, Tanita set to measure fat folds thickness, compass for measuring circumferences, measurement tape, 30 meter speed test and vertical jump test.

\section{Recommendations}

As per study results researcher recommends the following:

1. Be biological and physiological measurements resulting from the current study of the most important foundations that take into account when forming the National Football team speed.There should be continuity in periodic total measurements for female players.

2. Be biological and physiological measurements resulting from the current study of the most important bases for selecting responsive Alaabat starlets football speed This study results to be used in predicting speedball female players performance level.
3. Interest in the selection process for the players and ball speed players because of their importance in the proper direction of the training process in ball speed.Study results to be distributed to speedball teams and national team in Egypt.

4. Directing and training programs for rationing Balaobein sports teams under study according to the physiological and morphological characteristics resulting from the current study.

5. Continuity in the work on the Universal Periodic measurements players.

6. Predict the level of performance of the players ball speed in the light of the results of this study.

7. Identify the stages of athlete development in light of the characteristics of the conclusions arrived at by this study.

8. Work to disseminate the findings of research on the clubs and football teams speed in the Arab Republic of Egypt.

9. Conduct similar studies on other samples and different sports, individually and collectively.

10. Guided by the results of this study in further studies to compare the morphological and physiological measurements differentiated between players and football players local and international speed and to identify the current level and improve it.

\section{References}

1. Abul Ela Abdel Fattah (1985): Talent selection in sports field, Alam ElKotb, Cairo.

2. Ashraf Nabih Ibrahim Mohammed (2002): Biological profile of Egyptian national teams players in some individual sports, unpublished Master thesis, Faculty of Physical Education for men, Helwan University.

3. Farouk Rajab Ahmed Saleh: "football speed law" normalized trade Ahram, Qalyoub, Egypt, 1993.

4.

Franck leGall,Christopher Carling, Mark Willia ms,Thomas Reilly(2008):Anthropometric and fitness characteristics of international, professional and amateur male graduate 
soccer players from an elite youth academy Journal of Science and Medicine in Sport.

5. Geyhan Youssef El Sawy (1999): Biological profile for taekwondo as a basis for selection process, unpublished $\mathrm{PhD}$. thesis, , Faculty of Physical Education, University of Zagazig. Farouk Rajab Ahmed Saleh: "football speed law" normalized trade Ahram, Qalyoub, Egypt, 1993.

6. Heller ,J,Peric, T.Dlouhd,Pries, T.Kohlika,E. Melichna ， J. Nouakona ,H . ( 1998 ): "Physiological Profiles of Male and Female Taekwondo ( ITF) Black belts",London.

7. Jayasudha Katralli \& Shivaprasad S. Goudar (2012 ) : Anthropometric Profile and Special Judo Fitness levels of Indian Judo Players Asian Journal Sports Medicine

8. Mohamed Sobhi Hassanein (1998): Atlas for body patterns classification and characterization, 1st ed., AlKetab publishing center, Cairo.

9. Mohamed Nasreddin Radwan (1998): Methods of physical effort measurement in sports, AlKetab publishing center, Cairo.

10. Mohamed Nasreddin Radwan: "reference in physical measurements" i 1, Arab Thought House, Cairo, 1997.Saad Kamal Taha (1996): Biology principles, 1st. ed., Maadi Press, Cairo.
11. Mr. Mouawad Mr. Hosseini (2001): "Some of the determinants of emerging fencing selection and their relative contribution to the level of achievement", Ph.D. thesis, Faculty of Education, University of Al-Azhar.

12. Saad Kamal Taha (1996): the principles of diversity, the first edition, Press Maadi, Cairo.

13. Safia Gazar ElKasb El Agamy (2002): Studying some physical parameters for speedball female juniors' selection, unpublished Master thesis, Faculty of Physical Education, University of Alexandria.

14. Sahar Mohamed Ahmed (1996): Biological profile for heptathlon female players, unpublished Ph.D. thesis, Faculty of Physical Education for Girls, Helwan University.

15. Taaffe. D. Pieter, D, W ( 1990 ) : Physical and physiological characteristics of elite Teakwondo athletes, commonwealth international conference, Auckland, New Zealand

16. vila helena\& manchado carmen (2012): Anthropometric Profile, Vertical Jump, and Throwing Velocity in Elite Female Handball Players by Playing Positions Journal of Strength \& Conditioning Research. 